\title{
Gramática hebrea y gramáticas hispanas de los siglos XVI y XVII
}

\section{Hebrew grammar and Hispanic grammars in the 16th and 17th century}

\author{
SANTIAGO GARCÍA-JALÓN \\ Facultad de Filosofía. Universidad Pontificia de Salamanca. España \\ Correo electrónico: sgarciala@upsa.es
}

El artículo recoge las noticias que diversos especialistas han publicado sobre la presencia de la gramática hebrea en las obras de gramática escritas por autores hispanos de los siglos XVI y XVII y añade algunos datos nuevos. Contextualiza este fenómeno en el ambiente intelectual que se extiende por Europa en el siglo Xvi e identifica las obras de la tradición gramatical hebraica que contienen las nociones y términos usados por los gramáticos hispanos. Concluye postulando la conveniencia de emprender una investigación sistemática sobre la cuestión, revisando desde esta perspectiva las gramáticas misioneras.

Palabras clave: Gramática hebrea, Gonzalo Correas, Minerva, Gramáticas del náhuatl

This paper brings together several studies published by renowned researchers on the presence of Hebrew grammar in the grammatical works written by Hispanic authors in the 16th and 17th century, to which it adds new data. We frame this influence within the intellectual context prevailing in 16th-century Europe and identify the works of the Hebrew grammatical tradition containing the ideas and terms used by the Hispanic grammarians. Lastly, we conclude suggesting the convenience of taking up a systematic research on the matter, revising missionary grammars from this perspective.

Key words: Hebrew grammar, Gonzalo Correas, Minerva, Náhuatl grammars 
En los últimos años, repetidamente se ha hecho notar que la gramaticografía hebrea del siglo XVI fue utilizada por los autores que en esa centuria y en la siguiente escribieron gramáticas de distintas lenguas, entre ellas del latín, el español o las lenguas amerindias (Sáenz de Zaitegui 2010).

La identificación de este hecho es relativamente reciente. Prescinden de él los editores de las obras del Brocense o el maestro Gonzalo Correas (Alarcos 1954; Taboada 1984 y Sánchez Salor y Chaparro 1995). Cuando en 1997 Zimmermann coordina La descripción de las lenguas amerindias en la época colonial, los especialistas que colaboran en el volumen eluden ocuparse de cuanto se refiere al hebreo, a pesar de que algunos de ellos reproducen pasajes de gramáticas de dichas lenguas que expresamente remiten a la hebrea. Otro tanto hacen los autores de los trabajos editados en 2000 por Zwartjes.

No es de extrañar que los estudiosos aludidos procedieran como lo hicieron. El escaso conocimiento de las obras de gramática hebrea publicadas en el s. Xvi y de sus contenidos impedía que los investigadores atendieran a su influjo en las gramáticas de otros idiomas.

El presente estudio quiere contribuir a remediar esta deficiencia. Se propone recopilar las observaciones sobre la materia que han sido hechas ya por diversos expertos, pero abordando el asunto desde la vertiente de la lingüística hebrea. De este modo, se completarán dichas observaciones tratando de precisar las fuentes hebreas empleadas por los gramáticos cuya obra se examine. Se aportarán, además, algunos datos nuevos, de suerte que sea posible calibrar mejor las proporciones reales de la presencia de los gramáticos hebreos del xVI en la gramatización de otras lenguas elaborada en la época.

\section{La gramática hebrea EN EUROPA EN EL SIGLO XVI}

En el siglo Xvi tiene lugar la publicación de una sorprendente cantidad de obras de gramática hebrea: en esa centuria salen de las prensas europeas tres centenares de títulos distintos, muchos de los cuales conocen múltiples reediciones (García-Jalón y Veiga 2000). Habrá que esperar hasta la segunda mitad del siglo xx, una vez instaurado el estado de Israel, para asistir a la repetición de una actividad editorial de tales dimensiones en el campo de la gramaticografía hebrea.

Para valorar adecuadamente la magnitud de este fenómeno hay que tener en cuenta que, por las mismas fechas, los tratadistas apenas se ocupan de otras lenguas semíticas y que escasean incluso los escritos sobre gramática de las lenguas clásicas o vernáculas.

Varios factores pueden explicar este inusitado interés por el hebreo. En primer lugar, la divulgación del ideal de vir trilinguis y el deseo de acceder a los estudios bíblicos con una dotación técnica mucho mejor que la acostumbrada en la Edad Media. Además, la aplicación a la lengua hebrea de los modelos empleados para el análisis de las lenguas clásicas permite una descripción coherente del hebreo y facilita su estudio. Añádase a ello que, a diferencia de lo que ocurría en la Edad Media, cuando las gramáticas hebreas se escribían 
en hebreo o en árabe, las del xvi están escritas en latín, circunstancia que las hace accesibles a un elevado número de lectores. Por último, las nuevas actitudes intelectuales inspiradas por la Reforma alientan la voluntad de mantener una relación inmediata con los textos de las Sagradas Escrituras.

Pero, al margen de los motivos más o menos "prácticos" que fomentaban el estudio del hebreo y de que tal estudio respondiera en uno u otro grado a los ideales de la época, la insistencia en componer gramáticas hebreas delata que el examen científico del hebreo resultaba por sí mismo seductor y que por sí mismo ofrecía interés.

Los análisis gramaticales de la lengua hebrea hechos en el xvi produjeron un efecto insospechado, sobre el que han llamado la atención diferentes historiadores (Robins 1987: 101-102 y Kessler-Mesgich 2000: 679). Percival (1984) resume dicho efecto diciendo que originó un primer esbozo de lingüística general, que se extendió entre los humanistas y determinó el modo en que afrontaban el estudio de las lenguas. Por esa vía, la perspectiva adquirida gracias a la familiaridad con el hebreo redundó igualmente en la expansión del español en América (Percival 1994: 70) y proporcionó nociones de la mayor utilidad para la caracterización de las lenguas amerindias (Lliteras y García-Jalón 2006).

En su origen, este proceso obedece al menos a dos hechos. El intento de troquelar la lengua hebrea con los moldes suministrados por la gramática de las lenguas clásicas pronto hizo evidente que no había una correspondencia exacta entre aquella lengua y éstas. En el siglo XIV, un franciscano francés, Nicolás de Lyra (c. 1270-1349), había señalado ya que el hebreo carece de optativo, apunte que repiten cien ańos más tarde sus traductores al español (García-Jalón 2010) y que adopta en el xvi el converso Alfonso de Zamora (c. 1476-c. 1544), quien recoge la misma observación en la segunda edición de su gramática hebrea (Zamora 1526: 6). A la par, la lengua hebrea presenta rasgos que, si se resisten a ser catalogados con las categorías gramaticales de las lenguas clásicas, ofrecen analogías con fenómenos que se registran en algunas lenguas romances y en los idiomas del Nuevo Continente.

De esta suerte, el hebreo y su gramática se convierten para los estudiosos del XVI y el Xvir en un gozne que les permite diseñar ese esbozo de lingüística general de que habla Percival y renovar el utillaje con que analizan tanto las lenguas clásicas como las vernáculas europeas y las de los pueblos indígenas con las que toman contacto a lo largo de esos siglos.

\section{SOBRE LAS PARTES DE LA ORACIÓN}

Son bien conocidas la importancia que los primeros gramáticos del Barroco concedieron al debate sobre cuántas son las partes de la oración y las referencias a la gramática hebrea que hacen a propósito de esta cuestión.

Casi al final de su vida, el maestro Gonzalo Correas (1571-1631) redacta su Arte de la lengua española castellana. Declarando los motivos que le inducen a componer esta obra, dice: "Io confieso que entre las otras causas que me movieron á hazer esta Arte fue la 
maior enseñar en ella la verdad de tres partes de orazion" (Alarcos 1954: 135). Y al poco añade: "Todas las palavras de las lenguas se rreduzen á tres xeneros, al nombre, al verbo, á la partícula, que en Hebreo llaman dizion" (Alarcos 1954: 138).

El parecer de Correas sobre este punto gozaba de abundantes y notables precedentes entre los gramáticos del siglo Xvi (Merrill 1970; Hernando 2009; Hernando 2010). A pesar de lo cual, nuestro autor decide apelar a la autoridad del "Hebreo". Los gramáticos de esta lengua mantienen casi unánimemente que las partes de la oración son tres, estructuran sus obras de acuerdo con esa convicción y denominan las partículas con el término "dizion" (García-Jalón 1998a: 31).

Pero aún más reveladoras de la influencia de la gramaticografía hebrea en el pensamiento de Correas son las siguientes palabras del Arte:

Las palavras de una lengua sea cualquiera son tres, porque todos los vocablos son en tres maneras, i se dividen en tres partes ó montones, i se reduzen a estos tres xeneros dichos nombre, verbo i particula, como está llano y asentado en Hebreo, Caldeo y Aravigo, i en todas las otras lenguas orientales i de Africa, i todas las del mundo convienen en esto; i era ansi claro y asentado antiguamente en Griego i Latin como lo rrefiere Iuan Isaak en su Arte Hebrea del otro Rrabino que dize en el Libro que escrivió contra el Rrei Cosdroas, que antes en Griego i Latin no avia mas de tres partes de oración (Alarcos 1954: 133-134).

Las opiniones expuestas por Correas en este pasaje y los términos con que se expresa coinciden casi literalmente con los que décadas antes había usado el Brocense (1523-1600) en su Minerva sive de causis lingua latine (1587):

Entre los hebreos son tres las partes de la oración: nombre, verbo y dicción con significado. Los árabes también establecen sólo estas tres partes: $f^{`} l$, verbo; ism, nombre; y harf, dicción. Todas las lenguas orientales tienen estas tres partes de la oración. Cierto rabino, que supuestamente discute con Cosdra, rey de los persas, sostiene que todas las lenguas tienen su origen en la hebrea, y que la griega y la latina sólo tuvieron en otro tiempo tres partes de la oración. Lo mismo piensa Plutarco en las Cuestiones de Platón; y san Agustín, en las Categorías, establece tres partes de la oración de acuerdo con la opinión de Aristóteles (Sánchez-Salor y Chaparro 1995: 48) ${ }^{1}$.

\footnotetext{
"Nam apud Hebræos tres sunt partes orationis: nomen, uerbum et dictio consignificans. Arabes quoque has tantum tres orationis partes habent: Pheal, uerbum; ismi, nomen; herph, dictionem. Quas tres partes orationis omnes linguæ orientales habent. Rabbinus, ille qui contra Cosdram regem persarum disputat, omnes linguas ab hebraica originem duxisse contendit, et graecam et latinam olim tantum tres orationis partes habuisse. Idem sentit Plutarchus in Quaestionibus Platonis; et diuus Augustinus in Cathegoriis ex Aristotelis sententia tres partes orationis constituit".
} 
La estricta coincidencia de contenidos y términos ha llevado a pensar que Correas se inspiraba en el Brocense e incluso que se limitaba a traducir un pasaje de la Minerva para incorporarlo a su propia obra (Merrill 1970: 109). Pero algunos datos impiden compartir este juicio.

El primero de ellos es la mención de "Iuan Isaak". Se trata de Iohannes Isaac Levita Germano (1515-1577). Nacido judío, se convirtió al luteranismo en 1547 y al catolicismo cuatro años más tarde. Desde esta última fecha, ejerció la docencia del hebreo en la universidad de Colonia (García-Jalón y Veiga 2000: 602-603). Publicó por entonces un De hebreorum grammatica liber (Isaac 1552) que a lo largo de las dos décadas siguientes conocería al menos cuatro reediciones. En esta obra se lee:

Los árabes también establecen sólo estas tres partes: $f^{\prime} l$, verbo; ism, nombre; y harf, dicción. Todas las lenguas orientales tienen estas tres partes de la oración. Que la griega y la latina sólo tuvieron en otro tiempo tres partes de la oración, lo sostiene aquel Rabino que discute con Cosdra, rey de los persas, en el pasaje en que prueba que todas las lenguas tienen su origen en la hebrea. Mira también Quintiliano en el libro primero, cap. 6, cap. 7 (Isaac 1570: 18-19)2.

Como puede comprobarse, las palabras del Brocense son una réplica casi exacta de las que anteriormente había escrito Iohannes Isaac. Sólo se aparta de él para sustituir la cita de Quintiliano por las de Plutarco, Agustín y Aristóteles. Por consiguiente, cuando Correas repite doctrinas y fórmulas ya empleadas por el Brocense no lo está traduciendo, sino que consigna la fuente de la que éste toma sus observaciones.

Es muy probable que Correas estuviera familiarizado con los escritos de Isaac y que, por tanto, fuera capaz de identificar la fuente empleada por el Brocense. Estudiante del Colegio Trilingüe de Salamanca, desde 1610 hasta su muerte ocupó en la Universidad de esta ciudad la "cathedra de propiedad de Lenguas que llaman de Hebreo" y hay noticia de que llegó a componer una gramática hebrea, que no se nos ha conservado.

Además, de la edición de 1570 de la gramática de Isaac se conserva un ejemplar en la Biblioteca de la Universidad de Salamanca (García-Jalón 1996: 68-69). Es posible que ese libro perteneciera a Correas o que formara parte de la colección del Colegio Trilingüe, colección cuyos fondos se trasladaron en buena parte a la mencionada biblioteca universitaria (García-Jalón 1998b: 460).

Hay un segundo aspecto digno de notarse en la versión que Correas ofrece del texto de Isaac empleado también por el Brocense. Ambos apelan al escrito de un rabino dirigido

\footnotetext{
2 "Arabes quoque tantum tres has Orationis partes habent: Pheal Verbum, Ismi Nomen, Herph Dictionem. Quas tres Partes orationis omnes linguæ Orientales habent. Græcam et Latinam olim non nisi tres Orationis partes habuisse, contendit Rabinus is qui contra Cosdram regem Persarum disputat, eo in loco quo probat omnes linguas ab Hebraica originem duxisse. Vide quoque Quintilianum libro primo, cap. 6, cap 7”.
} 
a "Cosdra, rey de los persas"3. Pero mientras que el Brocense, siguiendo a Iohannes Isaac, esgrime ese escrito para acreditar que el hebreo es la lengua primigenia y demostrar así que también el griego y el latín originalmente tenían sólo tres tipos de palabras, Correas elude esta argumentación: prescinde de las razones históricas y extiende a todas las lenguas la característica de contar sólo con tres géneros de palabras.

En parte esto puede deberse a que, a diferencia de lo que ocurre con la Minerva, el Arte de Correas es una gramática del español y, por tanto, a su autor no le interesa sólo lo que sucede con el latín y el griego, sino lo que ocurre con el castellano. Por eso, eleva a la categoría de rasgo universal lo que en el Brocense era sólo un hecho histórico.

Por otro lado, parece que Correas no concedía mayor beligerancia a la idea de que todas las lenguas procedían del hebreo y que ésta era la lengua natural por antonomasia (Alarcos 1954: 131-133). Sin discutir la especial dignidad de la "lengua santa", prefiere no entrar en los debates acerca de su naturaleza y de su relación con los demás idiomas.

De esta actitud cabe inferir que cuando extiende a todas las lenguas la propiedad de constar de tres tipos de palabras, Correas está pensando en una característica natural del lenguaje compartida por todos los idiomas.

Justamente ésta era la opinión que había mantenido Sanctes Pagnini (1470-1536), un dominico profesor de hebreo en La Sapienza y luego en Lyon. En 1526 publica una gramática de la lengua hebrea, reeditada en 1549. A ella pertenece esta aseveración: "Toda lengua (como testimonian R[abí] Ionah [Ibn Ganah] en Richmah y R[abí] David [Qimhi] en Michlol) tiene tres partes principales" (Pagnini 1549: 3) ${ }^{4}$.

Yonah ibn Ganah (c. 990-c. 1050) y David Qimhi (1160-1235), los autores citados por Pagnini, son dos eminentes gramáticos hebreos medievales cuyas obras eran bien conocidas en la Edad Media y se editaron varias veces a lo largo del xvi.

Quizás inspirándose en ellos, uno de los primeros autores cristianos que redactó una gramática hebrea, Roger Bacon (1214-1294), al tratar de las partes de la oración, escribía: "la gramática es sustancialmente la misma en todas las lenguas, aunque experimente variaciones accidentales" (Mounin 1983: 122). En el mismo sentido y con particular contundencia, Saadia ibn Danán (1430/1440-1490) postulaba: "el discurso se clasifica de modo necesario en toda lengua en tres grupos: nombre, verbo y partícula” (Valle 2004: 135).

En suma, Correas puede ampararse en la doctrina de Pagnini y en la tradición de la gramática hebrea para sostener que, por naturaleza, las partes de la oración son en cualquier lengua sólo tres, yendo así más allá de lo que el Brocense había defendido.

\footnotetext{
3 Permanecen sin identificar el autor y la obra a las que se refiere Correas, autor y obra que formaban parte de los tópicos de la historiografía lingüística de la época.

“Omnis lengua (ut testantur R[abí] Ionah [Ibn Ganah] in Richmah et R[abí] David [Qimhi] in Michlol) tres habet principales partes”. El Sefer ha-Rikmah es la traducción hebrea de la gramática de Yonah ibn Ganah, originalmente compuesta en árabe con el título de Kitab al-luma' (Vilenski 1931). El Miklol es la gramática de David Qimhi, editada ya en 1545 por Daniel Bomberg en Venecia (García-Jalón y Veiga 2000: 584).
} 
Correas da todavía un paso más cuando mantiene que de esas partes sólo dos, el nombre y el verbo, son "forzosas", mientras que la partícula es "azesoria" (Alarcos 1954: 133; 137 y 366 y García-Jalón y Lliteras 2006: 670).

También en este punto nuestro autor contaba con precedentes entre los gramáticos españoles. En 1558, Cristóbal de Villalón († c. 1588) publica en Amberes su Gramática castellana (García 1971). A propósito de los tipos de palabras, enseña:

Puedesse tambien considerar la clausula Castellana quanto al todo junto, que como emos dicho se liga y uñe de partes nombre y verbo como de prinçipales y de otras menos prinçipales (García 1971: 56).

La misma doctrina se encuentra algunos años antes en la gramática hebrea de Clenardo (c. 1494-1542), un belga profesor en París, que se estableció luego en Portugal y Espańa. Su Tabula in grammaticen hebraam (1529) gozó de enorme éxito: superó las veinte ediciones y, de creer al autor, de ella se vendieron un año en París en torno a 300 ejemplares. Allí comenta Clenardo: "El nombre y el verbo tienen mayor importancia que las demás partes de la oración, si alguien conociera bien estas dos yo le diría que estuviera seguro de lo demás" (Clenardo 1529: 29)5 .

La de Clenardo quiere ser una gramática eminentemente didáctica, lo que explica el tenor de su comentario. Pero éste se apoya en una reflexión teórica multisecular protagonizada por los gramáticos hebreos. A finales del siglo x, Yehuda ben Hayyuy había sostenido la misma opinión y de él la toma David Qimhi en el XIII (García-Jalón 1998a: 6567). En el xv Saadia ibn Danán enseña que usando sólo de nombre y verbo puede formarse un enunciado completo (Valle 2004: 137).

Nunca es fácil determinar hasta qué punto un autor se inspira directamente en otros. Razones hay para sospechar que Villalón tuviera noticia de la obra de Clenardo o, al menos, del pensamiento a ella subyacente. Villalón, que era de origen judío, se preciaba de ser estudioso de la Biblia, así es que cabe pensar que tuviera alguna familiaridad con el hebreo.

No obstante, hay que recordar que los gramáticos hebreos, tanto medievales como renacentistas, conocían la tradición gramaticográfica del mundo clásico. Por ejemplo, Pagnini, citando a Qimhi, dice: "El nombre significa a modo de sustancia, el verbo, en cambio, a modo de accidente" (Pagnini 1549: 3) . $^{6}$ Pero Platón es autor de unas palabras de contenido similar que hallamos reproducidas en la Minerva:

Todo lo que se enuncia, o es permanente, como árbol y duro, o es fluyente, como corre y duerme. Llamamos cosas permanentes o constantes a aquellas cuya naturaleza dura largo tiempo; a la marca de estas cosas se la llamó nombre.

\footnotetext{
5 "Orationis partes nomen et verbum plus cæteris habent negotii, quæ duo si quis probe norit eum de reliquo iubeam esse securum”.

6 "Nomen significat per modum substantiæ, verbum, vero, per modum accidentis".
} 
Llamamos fluyentes a aquellas cosas que duran sólo mientras ocurren. La marca de éstas es el verbo (Sánchez-Salor y Chaparro 1995: 48)7 .

En suma, la historia de la gramática se presenta como un crisol de diversas corrientes conceptuales en el que cada una de ellas se enriquece y perfila al contacto con las demás. Conviene por eso ser cauteloso a la hora de identificar relaciones entre los autores y es preferible emplear un criterio restrictivo.

\section{LA GRAMATICOGRAFía HEBREA EN LAS GRAMÁTICAS DE LA LENGUA MEXICANA}

Los progresos hechos en la reflexión gramatical por efecto de la incorporación de la gramaticografía hebrea redundaron también en la gramatización de las lenguas amerindias. Niederehe afirma que la elaboración de las llamadas "gramáticas misioneras" fue hecha "con la gramática latina de Nebrija en el bolsillo" (Niederehe 2001: XIV). Sin negarlo, hay que añadir que los autores de esas gramáticas portaban también en sus manos gramáticas de la lengua hebrea.

No cabe olvidar que la primera gramática hebrea impresa en lengua española ${ }^{8}$ fue obra del franciscano Martín del Castillo, que pasó buena parte de su vida en México, dedicado a la docencia y a la formación de los candidatos a profesar en su orden (Osorio 1989: 88). Impresa en 1676, en Lyon, casi un siglo más tarde era copiada a mano por el jesuita Pedro Alegría, a pesar de que por las mismas fechas desaconsejaba su uso el Catedrático de Hebreo de los Reales Estudios de San Isidro (Azcárraga 2004: 78-79). El manuscrito original de la misma se conserva en la Biblioteca Nacional de México (Reinhardt 1990: 105). De suerte que hay constancia de que en el siglo xvir estaba implantado en México el conocimiento de las lenguas bíblicas.

Pero las noticias que tenemos nos permiten ir más allá. Ascensión Hernández de León-Portilla ha identificado al menos tres referencias al hebreo en el Arte de la lengua mexicana y castellana de fray Alonso de Molina (1571). El autor (1513-1579) residió la mayor parte de su vida en el convento de San Francisco de la ciudad de México, donde pudo disponer de algunas obras de gramática hebrea (Hernández de León-Portilla 2009: 173).

Repasemos las citaciones del hebreo hechas por Molina tal y como han sido registradas por Hernández de León-Portilla. La primera de ellas atańe a "una letra hebrayca que es la tsade" (Molina 1571: 5).

\footnotetext{
"Quidquid enuntiatur, aut est permanens, ut arbor, durum; aut fluens, ut currit, dormit. Res permanentes siue constantes uocamus, quarum natura diu perstat; harum notam nomen dixere. Fluentes dicimus quarum natura est esse tandiu quandiu fiunt. Harum nota uerbum est".

$8 \quad$ Para ser exactos, el de Martín del Castillo no es el primer texto de gramática hebrea escrito en español. Los folios 80-159v y 184-304v del Mss. 4188 de la Biblioteca Nacional de España contienen la traducción al español de parte de la gramática de David Qimhi hecha por Alfonso de Zamora.
} 
Correspondiente a la alveolar africada $/ \$ / \ldots$ se ha de "escribir con $t$. y s. o con $t$. y $z$. y "ase de pronunciar como t. y. $s$ ". Esta pérdida de oposición entre $s$. y $z$. la corrige en la segunda edición del Arte, de 1576, donde afirma que "la letra hebrayca se ha de escrevir con $t$. y $z$. y ase de pronunciar como tal" (Hernández de León-Portilla 2009: 174). franciscano:

En segundo lugar, refiriéndose al verbo en náhuatl, comenta el gramático

Es aquí de notar que comummente segun la costumbre de los hebreos, en todos los tiempos y modos se forman las otras personas de la tercera como de tetlaçotla. se dize nitetlaçotla. yo amo (Molina 1571: 51v).

El fenómeno lingüístico señalado por Molina tiene lugar, ciertamente, en el hebreo. En esta lengua, la raíz verbal aparece en la tercera persona masculina del llamado tiempo "perfectivo" en la conjugación más sencilla. A partir de ella, mediante afijos, se forman el resto de las personas, tanto del perfectivo como del resto de los tiempos y conjugaciones. Por esta razón, en los diccionarios hebreos las entradas de los verbos no se hacen reproduciendo los infinitivos, sino las antedichas terceras personas.

Ateniéndose a esta práctica, escribe Molina en el Prólogo a su Vocabulario enla lengua Castellana y Mexicana (1555):

Todos los verbos dela lengua se pondran en la primera persona del presente del indicativo, si la tuvieren, y si no en la tercera, porque esta todos los verbos la tienen: y sirve siempre una mesma para singular, pero el romance de los verbos sepondra en el infinitivo, como lo pone Antonio de Lebrixa en su vocabulario (Percival 1994: 71-72).

Molina, que cita la autoridad de Nebrija para avalar el uso de los infinitivos en la traducción al romance de los verbos náhuatl, obvia en el Vocabulario que el empleo de las personas para lexematizar los verbos es común en hebreo. La opción que elige sintetiza dos métodos lexicográficos: el habitual en hebreo y el empleado para el castellano por Nebrija.

De esta manera, está poniendo en práctica el programa al que quiere atenerse en su gramática, según el cual no es posible valerse de un solo método para exponer las lenguas indígenas, sino que se requiere acudir al que sea necesario en cada caso (Percival 1994: 71).

Estas apelaciones al hebreo resultan especialmente interesantes. Parecen suponer que los destinatarios de la obra de Molina conocen esa lengua, pues el recurso a este idioma tiene una intención didáctica. No se trata tanto de autorizar mediante el uso hebraico la legitimidad de una determinada tesis gramaticográfica, sino más bien de ilustrar con el caso del hebreo el hecho descubierto en el náhuatl.

Por último, considera Molina que hay dos clases de sílabas: 
las vnas que se llaman serviles por quanto siruen a muchos nombres o verbos para conocer la diferencia que puede auer entre el nombre y el verbo. [Las otras son] las de la rayz, después de la qual se ponen las letras o sillabas seruidoras (Molina 1571: 30v)

La clasificación de letras y sílabas en raíces y serviles había sido empleada ya por otro franciscano, Maturino Gilberti (1498-1585), quien en Uocabulario en la lengua Castellana y Mechuacana, de 1559, había escrito:

Siguen se ciertos verbos por el alphabeto, a los quales algunos quieren llamar rayces: porque parece que, apartados los miembros, o para mejor dezir los serviles quedara la rayz sin significar nada, como el tronco sin ramos: solamente dispuesto a producirlos (Percival 1994: 73-74 y Lliteras y García-Jalón 2006: 36-37).

La nomenclatura "radicales" y "serviles" cuenta con una larga tradición en la gramaticografía hebrea (Sáenz-Badillos 1986: 21-22 y Sáenz-Badillos y Targarona 1988: 32). Se encuentra ya en Saadia Gaón (892-942), de quien la recogen el poeta y gramático andalusí Menahem ben Saruq (c. 910-970) y Moseh Qimhi (c. 1127-c. 1190). A la autoridad de este último remite, ya en el xvi, el hebraísta francés Jean Chéradame (c. 1500-post 1543), que testimonia la difusión de esta doctrina entre sus contemporáneos (Chéradame 1532: 24), que la emplean de modo habitual (García-Jalón 1998a: 91).

Dicha tradición define como serviles las letras que se añaden a la raíz para indicar género, número, flexión, etc. Es decir, emplea el término en la misma acepción usada por Molina.

Pero los gramáticos del hebreo clasifican en virtud de esta división sólo letras y no sílabas. Eso da relevancia al hecho de que Molina extienda también a las sílabas la clasificación en radicales y serviles. De esta manera revela el modo en que procede: identificado un fenómeno en náhuatl, encuentra una analogía entre el mismo y otro del hebreo y traslada al primero de estos idiomas la terminología gramatical empleada en el segundo. No se trata de una aplicación mecánica, sino de una adaptación reflexiva.

Hasta aquí las menciones expresas del hebreo que hace Molina y consigna Hernández de León-Portilla. A las cuales hay que añadir todavía una referencia implícita a esa lengua que aparece también en Molina.

Se trata de los que el gramático franciscano llama "pronombres afijos" (Esparza 2007). Unos años más tarde volverá sobre ellos Antonio del Rincón (1555-1601) en el Arte mexicana (1595), denominándolos "semipronombres" y diciendo que "no tienen en si entera significación sino juntandose a otras partes de la oración” (Percival 1994: 74).

Sin embargo, habrá que esperar a Horacio Carochi (1579-1662) para que se desvele el recurso a la gramática hebrea que se da en el tratamiento de este fenómeno del náhuatl. En Arte de la lengua mexicana con la declaracion de los adverbios della (1645), enseńa el gramático jesuita: 
[Los semipronombres] siempre se componen con nombres, preposiciones, adverbios y verbos, y corresponden à los que en el Arte de la lengua Hebrea se llaman affixos, aunque los affixos Hebreos se posponen à los nombres, y verbos, y estos semipronombres a anteponen (Carochi 1645: 10).

Efectivamente, el hebreo expresa mediante sufijos distintas funciones sintácticas: el posesor, en los nombres; el objeto directo en los verbos... Los gramáticos hebreos del XVI que se refieren a este tipo de partículas las catalogan entre las "diziones", pero les otorgan la calidad de "pronombres" (García-Jalón 1998a: 154).

Las palabras de Carochi recuerdan las que un par de décadas antes había escrito Correas a propósito de los pronombres enclíticos españoles:

Afixos se pueden llamar, que es asidos o fixados, como en Hebreo unas sílabas que tienen fixadas al fin de nombres i verbos, i particulas que llaman pronombres afixos, con quien tienen todos estos nuestros mucha semejanza en xuntarse, i aunarse con la prezedente (Alarcos 1954: 188).

El autor español y el italiano escriben con independencia uno del otro, pues la obra de Correas no llegó a publicarse. Esta circunstancia testimonia que ambos frecuentaban de manera directa la gramática hebrea e induce a pensar que tal hecho debía de ser habitual entre los lingüistas de la época.

\section{Conclusión}

Glosando la estima que Carochi sentía por la obra gramatical de Rincón, explicaba hace años Una Canger:

Cuando Carochi alaba a Rincón y subraya que enseña con 'tanto magisterio', es por la organización del Arte y también porque Rincón analiza la lengua no según el modelo latino, sino conforme a la lengua misma. Lo que ha adoptado Carochi de Rincón es precisamente la organización del Arte (Canger 1997: 67).

Que Rincón prescindiera del modelo latino para analizar el náhuatl y se atuviera a la lengua misma no implica sino que recurría al bagaje conceptual que le suministraba el conjunto de obras gramaticales que tenía a su disposición, entre ellas las dedicadas al hebreo.

Repasar a la luz de las gramáticas hebreas del xvi algunos textos de gramáticas de otras lenguas escritas en la misma época desvela la familiaridad que los autores de éstas tenían con aquéllas y la frecuencia con que acudían a ellas para precisar los análisis lingüísticos que pretendían llevar a cabo. 
Pero, al mismo tiempo, hace evidente que, como debió de ocurrir también en Europa, el conocimiento del hebreo alcanzó un considerable grado de difusión entre los ilustrados y los eclesiásticos de al menos parte de los territorios del Nuevo Continente. Esta circunstancia, sobre la que llamó la atención en su día Osorio, contribuye a explicar la publicación de la gramática de Martín del Castillo que, a la luz de los datos expuestos, arraigaba en una larga tradición de estudios hebraicos en el Nuevo Mundo, protagonizada a la par por franciscanos y jesuitas.

Por fin, la recopilación de datos que se ha hecho permite argumentar convincentemente que quizás conviniera emprender un estudio sistemático de la presencia de la gramática hebrea en las gramáticas de otras lenguas escritas en los siglos XVI y XVII, prestando especial atención a las "gramáticas misioneras" que no han sido examinadas desde esta perspectiva.

\section{OBRas Citadas}

Alarcos García, Emilio (ed.). 1954. Gonzalo Correas. Arte de la lengua española castellana. Madrid: CSIC.

Azcárraga, Ma Josefa de. 2004. "Otros manuscritos”. En Francisco Javier del Barco. Catálogo de manuscritos hebreos de la Comunidad de Madrid. Volumen 2: Manuscritos hebreos en la Biblioteca Nacional, Archivo Histórico Nacional y Museo Lázaro Galdiano; manuscritos biblicos y obras gramaticales en la Real Academia de la Historia. Madrid: CSIC. 63-83.

Canger, Una. 1997. “El Arte de Horacio Carochi”. En Klaus Zimmermann ed. La descripción de las lenguas amerindias en la época colonial. Frankfurt/Madrid: Vervuert/ Iberoamericana. 59-74.

Carochi, Orazio. 1645. Arte de la lengua mexicana con la declaracion de los adverbios della. México.

Castillo, Martin del. 1676. Arte Hebraispano: Grammatica de la Lengua Santa en idioma Castellano. León de Francia (Lyon): Florian Anisson.

Chéradame, Jean. 1532. Ioannis Cheradami alphabetum lingue sancte, mystico intellectu referto. Paris: Gourmont.

Clenardo, Nicolas. 1529. Tabula in grammaticen hebream. Lovaina: Martens.

Esparza, Miguel Ángel. 2007. "Nebrija y los modelos de los misioneros lingüistas del Náhuatl”. En Otto Zwartjes, Gregory James y Emilio Ridruejo eds. Missionary Linguistics III/Lingüistica misionera III Morphology and Syntax. Amsterdam/Philadelphia: John Benjamins. 3-40.

García, Constantino (ed.). 1971. Cristóbal de Villalón. Gramática Castellana. Madrid: CSIC. García-Jalón, Santiago. 1996. Inventario de las gramáticas hebreas del siglo XVI de la Biblioteca General de la Universidad de Salamanca. Salamanca: Universidad Pontificia. . 1998a. La gramática hebrea en Europa en el siglo XVI. Guía de lectura de las obras 
impresas. Salamanca: Universidad Pontificia.

1998b. "Gramáticas hebreas del siglo xvI en la Biblioteca del antiguo Colegio

Trilingüe salmantino". Helmantica 150: 455-467.

2010. "Conceptos lingüísticos en la traducción medieval castellana de Nicolás de

Lira”. En Carlos Assunçao, Gonçalo Fernandes y Marlene Loreiro eds. Ideias Linguísticas na Peninsula Ibérica (séc. XIV a séc. XIX). Münster: Nodus. Vol. I. 283-290. García-Jalón, Santiago y Margarita Lliteras. 2006. “Tradiciones hebraicas en las Artes del maestro Gonzalo Correas”. En Antonio Roldán, Ricardo Escavy, Eulalia Hernández, José Miguel Hernández y Ma Isabel López eds. Caminos actuales de la historiografía lingüistica. Murcia: Universidad de Murcia. Vol. II. 663-675.

García-Jalón, Santiago y Manuel Veiga. 2000. "Repertorio de gramáticas hebreas impresas en Europa en el siglo Xvi. Autores, obras y ediciones". Helmantica 156: 535-731.

Gilberti, Maturino. 1559. Uocabulario en la lengua Castellana y Mechuacana. Ciudad de México: Juan Pablos.

Hernández de León-Portilla, Ascensión. 2009. "El arte de la lengua mexicana y castellana de fray Alonso de Molina: morfología y composición”. Estudios de Historia Novohispana 39: 167-206.

Hernando Cuadrado, Luis Alberto. 2009. "La partícula en Gonzalo Correas". Dicenda. Cuadernos de Filología Hispánica 27: 83-107.

. 2010. "El tratamiento de las partes de la oración en el Arte de la lengua española castellana de Gonzalo Correas". Boletín de Filología XLV: 259-278.

Isaac, Iohannes. 1552. De hebraorum grammatica liber. Louvain: Martinus Rotarius. . 1570. Grammatica hebrea absolutissima. Amberes: Plantin.

Kessler-Mesgich, Sophie. 2000. "L'étude de l'hébreu et des autres langues orientales à l'époque de l'humanisme". En Sylvain Aroux, E.F.K. Koerner, Hans-Josef Niederehe y Kees Versteegh eds. History of the Language Sciences. Berlin-New York: Walter de Gruyter. 673-680.

León-Portilla, Miguel. 1983. Horacio Horacio. Arte de la lengua mexicana con la declaracion de los adverbios della. México: UNAM.

Lliteras, Margarita y Santiago García-Jalón. 2006. "Tradiciones hebraicas en el Arte Grande (1625) de Gonzalo Correas". Actas del v Congreso Internacional de la Sociedad Española de Historiografía Lingüistica. Murcia: Universidad de Murcia. 497-509.

Merrill, Judith S. 1970. "Las primeras clasificaciones tripartitas de las partes de la oración: Villalón y el Brocense". Nueva Revista de Filología Hispánica XIX/1: 105-110

Molina, Alonso de. 1555. Vocabulario en lengua castellana y mexicana. México: Juan Pablos. Molina, Alonso de. 1571. Arte de la lengua Mexicana y Castellana. México: Pedro Ocharte. Mounin, Georges. 1983. Historia de la lingüistica desde los orígenes al siglo XX. Madrid: Gredos.

Niederehe, Hans-Josef. 2001. "Introducción. La lingüística en el ámbito hispanohablante". En E. F. K. Koerner y Hans-Josef Niederehe eds. History of Linguistics in Spain. Historia de la lingüistica en España. Amsterdam/Philadelphia: John Benjamins, v. II. 
IX-XXII.

Osorio Romero, Ignacio. 1989. Conquistar el eco: la paradoja de la conciencia criolla. México: UNAM.

Pagnini, Sanctes. 1549. Hebraicas instituciones. Paris: Robert Etienne.

Percival, W. Keith. 1984. "The Reception of Hebrew in Sixteenth-Century Europe: The Impact of the Cabbala”. Historiographia Lingüistica XI 1/2: 21-38 . 1994. "La obra gramatical de Nebrija en el contexto de la hegemonía mundial europea”. En R. Escavy et al. Actas del Congreso Internacional de Historiografia Lingüistica I. Murcia: Universidad. 59-84.

Reinhardt, Klaus. 1990. Bibelkommentare spanischer Autoren (1500-1700). I. Autoren A-LL Madrid: CSIC.

Rincón, Antonio del. 1595. Arte mexicana. México: Pedro Balli.

Robins, R.H. 1987. Breve historia de la Lingüistica. Madrid: Paraninfo. 5a ed.

Sáenz-Badillos, Ángel ed. 1986. Menahem ben Saruq, Mabberet. Granada: Universidad de Granada.

Sáenz-Badillos, Ángel y Judit Targarona. 1988. Gramáticos hebreos de al-Andalus (ss. X-XII). Filología y Biblia. Córdoba: El Almendro.

Sáenz de Zaitegui, Ainhoa. 2010. "La presencia del hebraísmo en la gramaticografía española de los siglos XVI y XVII. Nota sobre una investigación”. Helmantica 61: 347-350.

Sánchez de las Brozas, Francisco. 1587. Minerva sive de causis linguae latinae. Salamanca: Renaut.

Sánchez Salor, Eustaquio y César Chaparro (eds.). 1995. Francisco Sánchez de las Brozas. Minerva o De causis linguc latine. Cáceres: Institución Cultural "El Brocense". Excma. Diputación Provincial de Cáceres y Universidad de Extremadura.

Taboada Cid, Manuel (ed.). 1984. Gonzalo Correas. Arte Kastellana (1627). Santiago de Compostela: Universidad.

Valle, Carlos del. 2004. La gramática hebrea de Ibn Danán en la versión árabe y hebrea, Madrid: Aben Ezra.

Villalón, Cristóbal de. 1558. Gramática castellana. Anvers: Guillermo Simón.

Vilenski, Mikhaal (ed.). 1931. R. Yonah Ibn G'anah. Sefer ha-rikmah. Berlin: ha-Akademyah le-madae ha-Yahadut.

Zamora, Alfonso de. 1526. Introductiones artis grammatica hebraica. Alcalá de Henares: Miguel de Eguía.

Zimmermann, Klaus (ed.). 1997. La descripción de las lenguas amerindias en la época colonial. Frankfurt/Madrid: Vervuert/Iberoamericana

Zwartjes, Otto (ed.). 2000. Las Gramáticas Misioneras de Tradición Hispánica (siglos XVIXVII). Leiden: Brill. 